\section{Power games cause sparks in physics, but biologists have learnt from evolution}

SIR — Ad Lagendijk, in his Essay ${ }^{\text {}}$ Pushing for power" (Nature 438, 429; 2005), draws a picture of the physics community dominated by aggressive males engaged in territorial combat and believes that these observations extend to other branches of science as well.

We beg to differ with him. We find biology to encompass a diversity of men and women, juniors and seniors, from around the globe.

At two conferences we have recently attended - the Ecological Society of America meeting in Portland, Oregon, in August 2004 and the International Botanical Congress in Vienna in July last year - women accounted for about a third of delegates and a similar proportion of session organizers and speakers.

Although women gave only about $19 \%$ of the keynote talks in Vienna, they were no less assertive than men in inviting themselves as keynoters for their sessions. (Sessions in Portland did not have keynote speakers, so cannot be compared.) Talks, whether good or bad, were rarely met by harsh or unfair criticism, and we did not feel that young scientists, non-native speakers or women were treated differently.

If physicists are to learn their lessons from evolution, they would do well to note that success does not come only to predatory males 'red in tooth and daw'. It requires smart adaptation, soft power and, at more advanced levels, cooperation, all of which result in substantial diversity.

Perhaps they will also find that working in a more diverse community is more fun than being territorial predators.

Peter Hietz, Manuela Winkler

Department of Integrative Biology, University of Natural Resources and Applied LifeSciences, Gregor Mendel Strasse 33, 1180 Vienna, Austria

\section{Power clashes limit science and reflect archaic values}

SIR - The story told in Ad Lagendijk's Essay ${ }^{\alpha}$ Pushing for power" (Nature 438, 429; 2005)

is very familiar to many of us who have chosen to make a living in science.

As Lagendijk points out, the archaic and myopic value system now used in science favours a limited set of outcomes, often at the expense of scientific progress. But this value system and associated behaviours have other, far-reaching consequences.

First, they can compromise the integrity of the scientific enterprise through tremendous pressure to publish.

Second, they may reduce the diversity of the workforce by attracting, rewarding and therefore retaining those who thrive in particular kinds of competitive environments - who are not necessarily those of greatest scientific ability, insight or creativity.

Third, they may limit the range and relevance of scientific pursuits and may devalue interactions between scientists and the public. Implicitly, this could reduce the potential to identify and address scientific issues of more global relevance.

The current reward system needs reassessing and reformulating in order to accommodate and reflect wider, more inclusive values.

Maria Uriarte ${ }^{\star}$, Kathleen Weathersł, Valerie Evinert

*Columbia University, Department of Ecology, Evolution \& Environmental Biology, 1200 Amsterdam Avenue, New York, New York 10027, USA

†Institute of Ecosystem Studies, Box AB, Millbrook, New York 12545, USA

\section{Science is an adventure, not a battle}

SIR — The world I inhabit, of experimental research in biological physics, is far from the cut-throat one described by Ad Lagendijk in his Essay "Pushing for power" (Nature 438, 429; 2005).

First, it is true that grants are often hard to obtain, yet almost everyone I know who has been willing to resubmit has ultimately been funded.

Second, many of the scientists I know at least those who are involved in table-top experiments - have been able to push their own research agenda without being tempted or pressured to form egregiously large groups.

Third, although physics meetings can seem acrimonious, referee reports by physicists tend to be fair and matter-of-fact. I find this preferable to biology meetings, where talks may be greeted with "Let me compliment you on your wonderful data", but new ideas are often rejected by grant and journal reviewers.

Fourth, in my experience many advisers shield their postdocs and allow them to make quiet progress.

There is certainly pressure to complete projects in a timely manner and for credit to be fairly parsed. But why should this be seen as an issue?

I do not wish to argue with Lagendijk, because we work in different fields in different countries. I simply want to let students and junior fellows realize that doing science can be a lifelong adventure, rather than a constant battle.

David Kleinfeld

Department of Physics, University of California,

San Diego, 9500 Gilman Drive, La Jolla,

California 92093-0374, USA

\section{Bias may be unintentional but it's still there}

SIR — Marlene Zuk and Gunilla Rosenqvist, in their Correspondence "Evaluation bias hits women who aren't twice as good" (Nature 438,$559 ; 2005$ ), give an interesting view of women in science. Having been married to each other for almost two decades while raising two children and becoming professors at our respective universities in Taiwan, we would like to offer our perspective.

We agree that the under-representation of women in science, especially at higher levels, is primarily the result of bias in academic evaluation. The first author of this Correspondence was warned by her female adviser early in her career that women "have to try harder and do better than men, just to be able to compete with men".

Actions intended to benefit women can also be used against them. A few years ago, the Taiwan legislature passed a workplace sex-equality law, in effect imposing quotas for women sitting on academic evaluation committees in Taiwan. One unhappy male faculty member questioned this quota by raising the question, in his university congress meeting: "Does a sex organ help a person to think [when evaluating] ?"

Perceptions of male-female interactions can affect women in science too. At a faculty meeting determining the shortlist for hiring last year, Y.-H. H. spoke on behalf of the only eligible female candidate. Afterwards, he was asked by a junior faculty member whether the hiring of this young woman would "spell trouble" for his wife in the future.

Stavros Busenberg, a former professor of mathematics at Harvey Mudd College in California, who died in 1993, once commented on racism in the immediate aftermath of the 1992 Los Angeles riot: "In order not be a racist, one must consciously try not to be one." We would say this applies to discrimination of all types.

Cathy W. S. Chen ${ }^{\star}$, Ying-HenHsieh $\dagger$ *Department of Statistics, Feng Chia University,

Taichung 407, Taiwan

tDepartment of Applied Mathematics,

National Chung Hsing University,

Taichung 402, Taiwan

Contributions to Correspondence may be submitted to corres@nature.com. They should be no longer than $\mathbf{5 0 0}$ words, and ideally shorter. They should be signed by no more than three authors; preferably by one. 